\title{
A Critical Appraisal of the Spectrum of Image Guided Fine Needle Aspiration Cytology: A Three Year Experience from a Tertiary Care Centre in Delhi
}

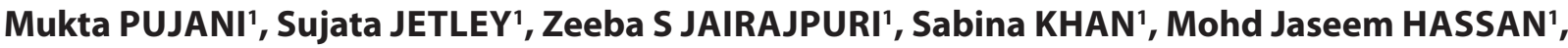 \\ Safia RANA', Mukesh KUMAR ${ }^{2}$
}

Department of ${ }^{1}$ Pathology and ${ }^{2}$ Radiology, Hamdard Institute of Medical Sciences \& Research, NEW DELHI, INDIA

\begin{abstract}
Objective: Image guided fine needle aspiration cytology (FNAC) is a safe, simple, rapid, cost effective and accurate modality in evaluation of deep seated lumps (abdominal, pelvic and intrathoracic masses) which are unapproachable by blind FNAC. In this study, a critical analysis of the utility of image guided FNAC in deep seated and otherwise inacessible mass lesions was carried out.

Material and Method: Fifty-four ultrasound (USG) or computed tomography (CT) guided FNACs from lumps at any location in the body, that is, thoracic, abdominal, pelvic etc over a period of 3 years (January 2012- December 2014) were included in the study. The most common site aspirated, the indications for a guided aspiration and the accuracy of aspiration cytology in comparison to the histological diagnosis were evaluated, wherever possible.

Results: Fifty-four image guided FNACs were performed (46 USG guided and 8 CT guided). Inconclusive, inflammatory, benign tumors, suspicious and malignant lesion rates were 5.6\%, 29.6\%, 11.1\%, 5.6\%, and 48.1\%, respectively. The most common site was the liver (25.5\%), followed by the thyroid (18.5\%), lung (14.8\%), gallbladder (11.1\%), and lymph nodes (7.4\%). Cytohistological correlation could be performed in 32 cases with a diagnostic accuracy of $100 \%$.
\end{abstract}

Conclusion: FNAC coupled with a diagnostic imaging technique such as USG or CT can improve the diagnostic yield and a definite diagnosis can be reached in most of the cases.

Key Words: Fine needle aspiration, Image guided biopsy, Ultrasound, Computerized tomography

\section{INTRODUCTION}

Fine needle aspiration cytology (FNAC) has been used as a primary modality for evaluation of all the palpable lumps in the body for a long time. However, its application is limited in cases with deep seated lumps, smaller sized lesions which are not readily palpable or if a small swelling is present in a crucial location, adjacent to major vessels. In such case scenarios, FNAC coupled with diagnostic imaging techniques such as ultrasound (USG) or computed tomography (CT) can improve the diagnostic yield and a definite diagnosis can be reached in most of the cases.

Image guided FNAC is a widely accepted diagnostic technique nowadays, and the applications are growing day by day. The technique is safe, simple, rapid, cost effective and accurate in the evaluation of deep seated lumps which are unapproachable by blind FNAC. Many studies over the years have evaluated the role of USG guided FNAC of various sites (1-8).

(Turk Patoloji Derg 2016, 32:27-34)

Received : 23.07.2015 Accepted : 31.10.2015
Image guided FNAC (both USG and CT guided) has a special role to play in abdominal, pelvic and intrathoracic masses. The relatively newer locations which are being explored include the thyroid $(9,10)$. The most significant advantage of USG guidance is that while performing the FNAC, one can visualize simultaneously whether the needle tip is within the target lesion. Moreover, if two pathologies coexist in a lump, blind FNAC may not yield the desired result while image guided FNAC can help localise a solid focus within an otherwise cystic lesion, especially in thyroid lesions. Thus, the precise focus with different echotexture can be sampled and an accurate diagnosis obtained. Moreover, mapping the vascularity of the lesion during FNAC can help the pathologist by avoiding vessel injury. The added advantage is that this provides an opportunity for a mutual interaction between the pathologist and the radiologist for the benefit of the patient. Any difference of opinion regarding diagnosis of a particular case can be addressed directly through discussion and a diagnosis of consensus can be arrived at.

Correspondence: Sujata JETLEY

Department of Pathology, Hamdard Institute of Medical Sciences \& Research, NEW DELHI, INDIA

E-mail: drjetley2013@gmail.com Phone: +919313850205 
The aim of this study was to analyze the spectrum of cytological diagnoses in deep seated mass lesions among the patient population catered to by our hospital. A critical analysis of the utility of image guided FNAC in the deep seated and otherwise inaccessible mass lesions was carried out. The most common site aspirated, the indications for a guided aspiration, utility over palpation guided FNAC, and the accuracy of aspiration cytology in comparison to histological diagnosis were evaluated, wherever possible. We also aimed to identify the lacunae in the guided FNAC procedure and reporting and to take the necessary measures to improve the service.

\section{MATERIAL and METHODS}

The study was conducted by the Department of Pathology in collaboration with the Department of Radiology of our institute. We provide a general cytology service so included all cases of USG and CT guided FNACs referred to the pathology department from lumps at any location in the body, that is, thoracic, abdominal, pelvic, etc., over a period of 3 years (January 2012- December 2014). A total of 54 image guided FNACs were performed during this period. The ultrasound machines which were used included the GE Voluson S-6 and Philips 350 Pro having color Doppler facility. The SIEMENS, SOMATOM Emotion 16 slice Multidetector CT scanner was used for CT guided FNAC.

The aspirations were performed by a pathologist in conjunction with a radiologist. Both air dried and 95\% alcohol fixed smears were prepared and stained with Giemsa, Papanicolaou, and Hematoxylin \& Eosin (H\&E) stains, respectively. Special stains such as Ziehl-Neelsen stain and Periodic Acid Schiff (PAS) were used when required. The FNAC diagnosis was correlated with clinical and radiological findings. The lesions were divided into the following categories: inconclusive, inflammatory, benign tumors, suspicious for malignancy, and malignancy.

\section{RESULTS}

A total of 54 image guided FNACs were performed during the study period. Image guided FNACs accounted for 6\% of all the FNAC done during this time period. The study group consisted of $61 \%$ males and 39\% females. Most of the patients belonged to the 41-60 years age group while malignancies were most frequently encountered in the 6180 years age group. The most common reason for image guided FNAC over a blind procedure was a deep seated location accounting for $74 \%$ of the cases, followed by small sized lesion to aid in localization ( $14.8 \%$ of cases) and close proximity to the vasculature (11.1\% of cases). Out of the total 54 FNACs, 46 FNACs were performed under USG guidance while 8 were performed under CT guidance. The detailed clinical profile of the study group is depicted in Table I. We analysed the requisition forms for their completeness and appropriateness of clinical and radiological details and observed that $75 \%$ of the forms did not have details like location of lump, laterality (left/ right/ bilateral), ultrasound findings, solid/cystic lump, size, and site from where FNAC was performed.

Out of a total of 54 cases, 3 FNACs (5.6\%) either yielded inadequate material or degenerated cells which were inconclusive for an opinion. These 3 cases were one each from USG guided FNAC of lesions from the liver, thyroid and CT guided FNAC from a lung lesion. Sixteen cases $(29.6 \%)$ were reported as inflammatory lesions including abscess, cysts, granulomatous lesion and tuberculosis. Benign tumors accounted for $11 \%$ of the cases while $5.6 \%$

Table I: Clinical profile of study group $(n=54)$

\begin{tabular}{|c|l|l|c|c|}
\hline & Characteristic & Categories & No of cases & Percentage \\
\hline 1. & Gender & Male & 33 & $61.1 \%$ \\
\hline & & Female & 21 & $38.9 \%$ \\
\hline 2. & Age & $<20$ years & 3 & $5.6 \%$ \\
\hline & & $21-40$ years & 17 & $31.5 \%$ \\
\hline & & $41-60$ years & 21 & $38.9 \%$ \\
\hline & & $61-80$ years & 13 & $24.0 \%$ \\
\hline 3. & Reason for guided FNAC & Deep seated location & 40 & $74.1 \%$ \\
\hline & & Small sized lesion (for localization) & 8 & $14.8 \%$ \\
\hline & & Proximity to vasculature & 6 & $11.1 \%$ \\
\hline 4. & Image Guidance & USG guided FNAC & 46 & $85.2 \%$ \\
\hline & & CT guided FNAC & 8 & $14.8 \%$ \\
\hline
\end{tabular}

FNAC: Fine needle aspiration cytology, USG: Ultrasound, CT: Computed tomography. 
were suspicious for malignancy as they only partly met the criteria for malignancy. The majority of the cases, that is $48.2 \%$, were diagnosed as malignancy. The pattern of distribution of cytological diagnoses is shown in Table II. Most of the cytology reports (82\%) were descriptive followed by an impression, and did not follow a uniform standard format of reporting. The most common sites were liver (25.5\%), followed by thyroid (18.5\%), lung (14.8\%), gallbladder (11.1\%), and lymph node $(7.4 \%)$. Cytopathology images from some interesting cases are shown in Figures 1-5.

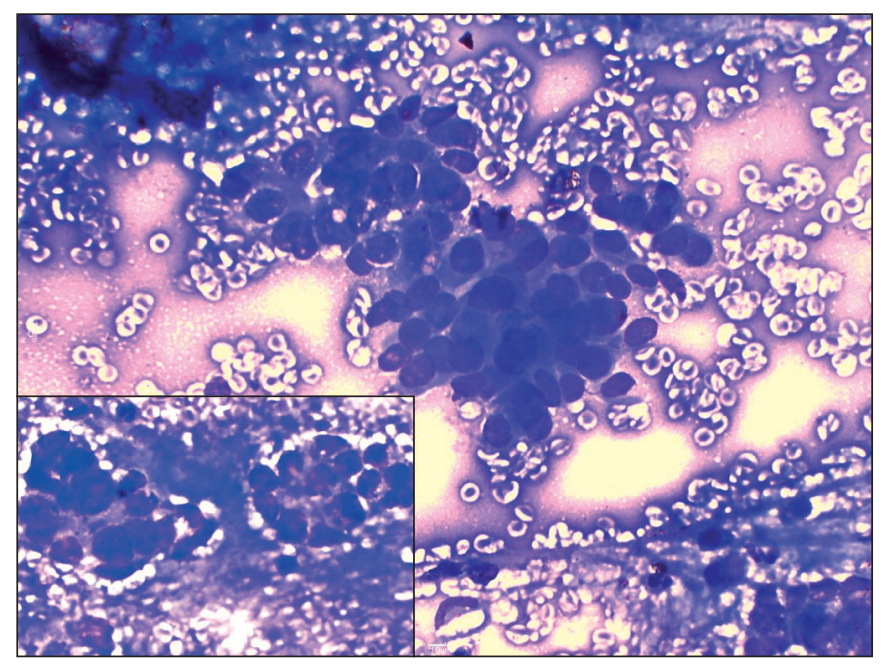

Figure 1: USG guided FNAC of liver mass (metastatic adenocarcinoma) showing atypical epithelial cells in clusters at places forming acinar pattern (inset) (Giemsa; x400).
Among the hepatic lesions ( $\mathrm{n}=14), 3$ cases turned out to be benign regenerative lesions, 4 were reported as abscesses while 1 case showed inadequate material. Among the malignancies, most of them were metastatic adenocarcinoma ( 5 cases) and only one case was diagnosed as hepatocellular carcinoma. Out of the 5 cases of metastatic carcinoma, 3 were from gall bladder carcinoma, and 1 each from stomach and lung. The cytological features which favoured a primary liver malignancy over a metastastatic malignancy were thickened cell cords (trabeculae) wrapped by endothelial cells, acinar pattern, transgressing vessels, macronucleoli, intranuclear inclusions and intracellular bile pigment. The diagnosis was suggested after clinicoradiological correlation.

Image guided thyroid FNAC was mainly performed for adequate localization of small thyroid lesions. Papillary carcinoma was detected in 3 cases, Hurthle cell neoplasm in 2 cases and one case each of colloid nodule, thyroiditis, follicular neoplasm, poorly differentiated carcinoma and inconclusive.

Table II: Pattern of distribution of lesions based on cytological features $(n=54)$

\begin{tabular}{|l|c|c|}
\hline Category of lesions & No of cases & Percentage \\
\hline Inconclusive & 3 & $5.6 \%$ \\
\hline Inflammatory & 16 & $29.6 \%$ \\
\hline Benign & 6 & $11.1 \%$ \\
\hline Suspicious of malignancy & 3 & $5.6 \%$ \\
\hline Malignancy & 26 & $48.1 \%$ \\
\hline
\end{tabular}

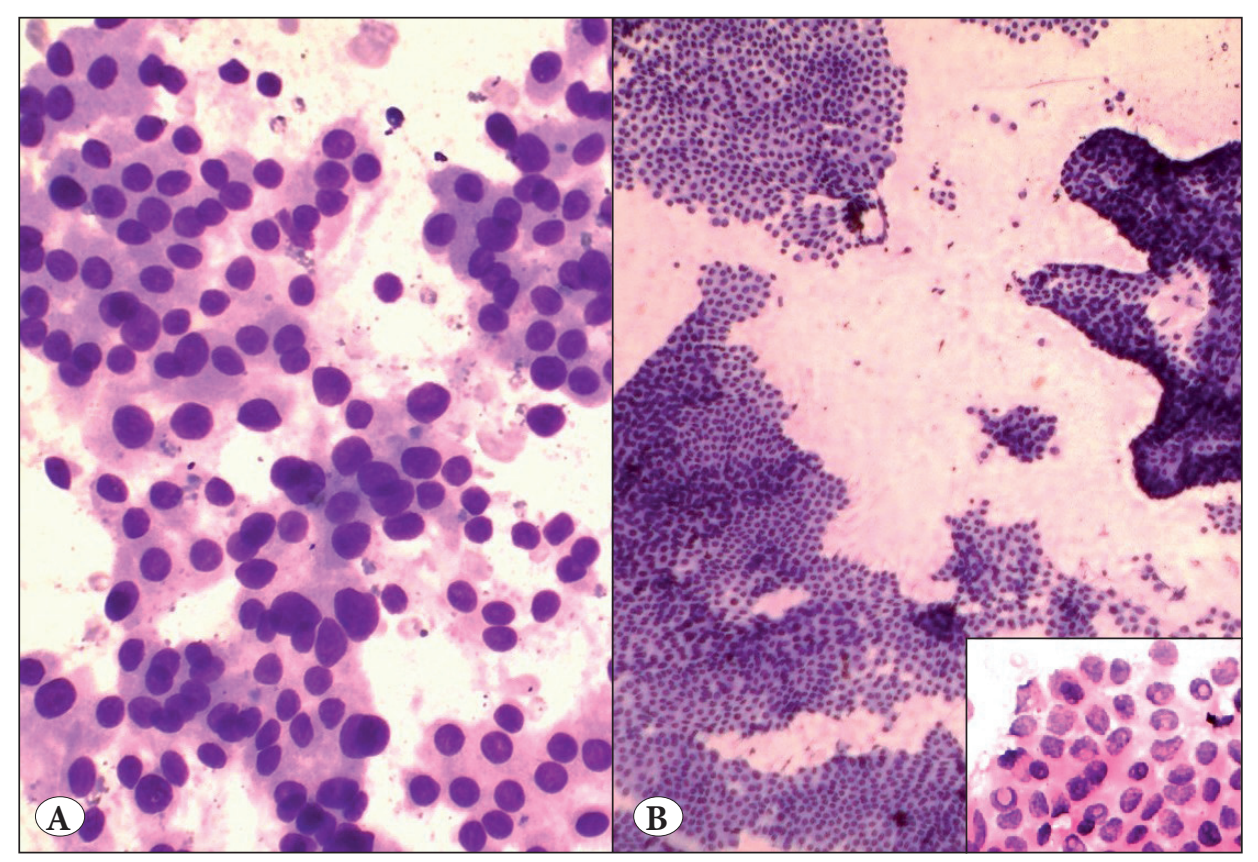

Figure 2: USG guided FNAC of thyroid lesions. A) Hurthle cell neoplasm showing sheets of cells displaying anisonucleosis (Giemsa; x400).

B) Papillary carcinoma with monolayered branching sheets and papillaroid clusters of follicular epithelial cells (Giemsa; x100) with intranuclear inclusions (inset, H\&E; x400). 


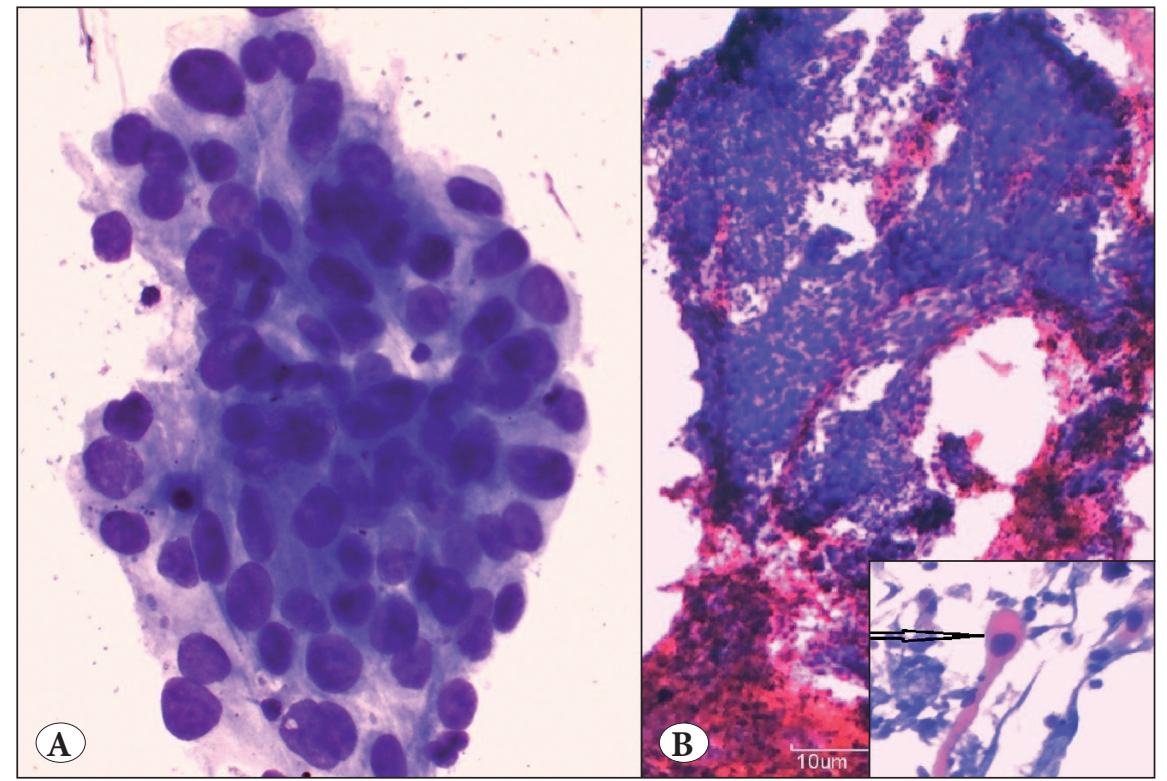

Figure 3: CT guided FNAC of lung lesions. A) Poorly differentiated carci-noma showing cluster of pleomorphic epithelial cells displaying anisonucleosis (Giemsa; x400).

B) Squamous cell carcinoma with sheets of atypical epithelial cells (H\&E; x100) and atypical squamous cell (tadpole cell) with dyskeratosis and hyperchromatic nucleus (inset, Papanicolaou; x400).

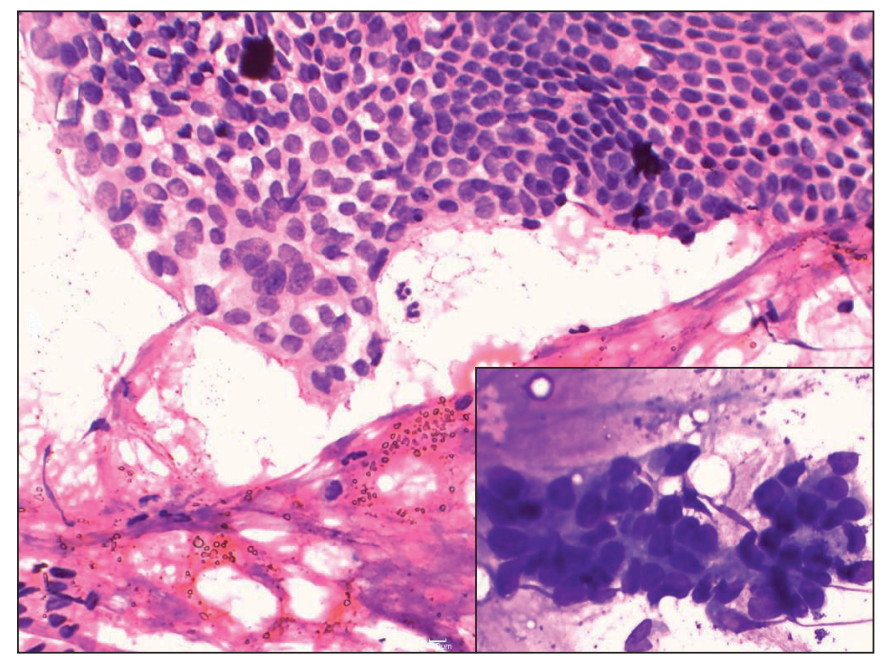

Figure 4: USG guided FNAC of intestinal mass. Mucin secreting adenocarcinoma showing sheets of atypical epithelial cells with mild to moderate anisonucleosis (H\&E; x100) against a background of mucin (inset, acinar pattern, Giemsa; x400).

FNAC of lung lesions were performed solely under CT guidance. Out of a total of 8 cases, 6 turned out to be malignant with adenocarcinoma being the most common (3 cases) while squamous cell carcinoma, small cell carcinoma and poorly differentiated carcinoma accounted for one case each. Histopathology was available for 4 cases with 3 being compatible with cytological diagnosis. One case was reported as an inflammatory lesion which was treated by antibiotic therapy. The case diagnosed as small cell carcinoma was referred to an oncology centre for chemo and radiotherapy. However, a case of poorly differentiated carcinoma was lost to followup.
Image guided FNAC of the gall bladder $(\mathrm{n}=6)$ yielded only malignant diagnoses, all adenocarcinomas. Guided FNAC of lymph nodes were performed either due to close proximity to a major vessel or on account of the deep seated location. Two cases turned out to be tubercular ( 1 in cervical nodes and 1 intraabdominal) while 2 were metastatic (one from papillary carcinoma of the thyroid and the other from gall bladder adenocarcinoma. Among GIT lesions for which USG guided FNAC was performed, 1 turned out to be inflammatory while 2 were diagnosed as adenocarcinoma. There were 2 cases of ovarian lesions, one being a case of primary infertility where endometriosis was suspected radiologically and confimed cytologically, the second case was diagnosed as a epithelial malignancy. The detailed cytological diagnosis of all the lesions is depicted in Table III.

Cytohistological correlation could be performed in 32 of the total 54 cases. The overall sensitivity was $92.59 \%$ (calculated as percentage of true positive cases from a total of true positives and false negatives), and specificity $100 \%$ (calculated as percentage of true negatives from a sum of false positives and true negatives). The diagnostic accuracy was $100 \%$ (calculated as percentage of sum total of true positive and true negative cases from the total number of cases). The discrepant cases included a case of USG guided FNAC liver which showed only regenerating hepatocytes without any atypical cells. On biopsy, it turned out to be adenocarcinoma. A case of CT guided FNAC lung revealed only inflammatory cell infiltrate and was reported as negative for malignancy. However, on histopathology it was a case of squamous cell carcinoma with dense stromal inflammation. Cytohistological correlation of all cases is depicted in Table IV. 
Table III: Spectrum of cytological diagnoses of all the lesions $(n=54)$

\begin{tabular}{|c|c|c|c|c|c|}
\hline Site of lesion & $\mathrm{n}(\%)$ & Inflammatory & n (\%) & Neoplastic & n (\%) \\
\hline \multirow[t]{3}{*}{ Liver } & $14(26)$ & Inconclusive & $1(7.1)$ & Metastatic Adenocarcinoma & $5(35.8)$ \\
\hline & & Abscess & $4(28.5)$ & Hepatocellular Carcinoma & $1(7.1)$ \\
\hline & & $\begin{array}{c}\text { Benign Regenerative } \\
\text { nodule }\end{array}$ & $3(21.5)$ & & \\
\hline \multirow[t]{4}{*}{ Thyroid } & $10(18.5)$ & Inconclusive & $1(10)$ & Hurthle cell neoplasm & $2(20)$ \\
\hline & & Colloid nodule & $1(10)$ & Follicular neoplasm & $1(10)$ \\
\hline & & Thyroiditis & $1(10)$ & Papillary carcinoma & $3(30)$ \\
\hline & & & & Poorly differentiated carcinoma & $1(10)$ \\
\hline \multirow[t]{4}{*}{ Lung } & $8(14.8)$ & Inconclusive & $1(12.5)$ & Adenocarcinoma & $3(37.5)$ \\
\hline & & Inflammatory & $1(12.5)$ & Squamous cell carcinoma & $1(12.5)$ \\
\hline & & & & Small cell carcinoma & $1(12.5)$ \\
\hline & & & & Poorly differentiated carcinoma & $1(12.5)$ \\
\hline \multirow[t]{2}{*}{ Gall Bladder } & $6(11.1)$ & & & Adenocarcinoma & $3(50)$ \\
\hline & & & & Poorly differentiated carcinoma & $3(50)$ \\
\hline \multirow[t]{2}{*}{ Lymph nodes } & $4(7.4)$ & Tubercular & $2(50)$ & Metastatic adenocarcinoma & $1(25)$ \\
\hline & & & & Metastatic Papillary carcinoma & $1(25)$ \\
\hline $\begin{array}{l}\text { Gastrointestinal } \\
\text { Tract }\end{array}$ & $3(5.4)$ & Inflammatory & $1(33.3)$ & Adenocarcinoma & $2(66.7)$ \\
\hline Ovary & $2(3.7)$ & Endometriosis & $1(50)$ & Carcinoma & $1(50)$ \\
\hline \multicolumn{6}{|l|}{ Miscellaneous } \\
\hline Retroperitoneum & $2(3.7)$ & Inflammatory & $1(50)$ & Malignant mesenchymal tumor & $1(50)$ \\
\hline \multirow[t]{2}{*}{ Epididymis } & $2(3.7)$ & Spermatocele & $1(50)$ & & \\
\hline & & Granulomatous lesion & $1(50)$ & & \\
\hline Spleen & $1(1.9)$ & Abscess & $1(100)$ & & \\
\hline Prostate & $1(1.9)$ & Benign hyperplasia & $1(100)$ & & \\
\hline Pancreas & $1(1.9)$ & & & Adenocarcinoma & $1(100)$ \\
\hline Total & $54(100)$ & & $22(40.74)$ & & $32(59.26)$ \\
\hline
\end{tabular}

\section{DISCUSSION}

The amalgamation of imaging modalities such as USG and CT with FNAC has improved the accuracy of diagnosis in patients presenting with deep seated lumps. USG guided FNAC has been in use for a long time now. In the initial phases, the applications of USG guided FNAC were limited to intra-abdominal lumps. Nowadays, newer locations are being explored.

The inadequacy rates for guided FNAChave a very wide range from $2.8 \%$ to $33.6 \%(8,11)$. The factors which influence this include: facility for on site adequacy evaluation, number of passes done, and the expertise of the pathologist and guiding radiologist. In the present study, the inadequacy rate was low (5.6\%) on account of using 2-3 passes per patient and all FNAC being performed by either consultants or senior residents. Ghosh et al. analysed the spectrum of cytological diagnosis and clinicoradiological correlation of guided FNAC over a period of 10 years (12).The cases included 234 CT guided and 266 USG guided FNAC. Adequacy ranged from $87.6 \%$ in CT guided FNAC to $91.7 \%$ in USG guided FNAC. They observed that an increased number of inadequate aspirates were obtained from very small sized and deeper lesions. In the index study, there were only 3 cases which did not yield diagnostic material including one case each of image guided FNAC of liver, lung and thyroid. The reasons were small size of lesion in case of the thyroid and lung and a very deep seated lesion of the liver.

When going through the literature, we came across various studies on image guided FNAC from various sites and observed that most of the authors reported fairly good sensitivity, specificity and diagnostic accuracy. Sheikh et al. evaluated 120 cases of abdominal and thoracic masses 


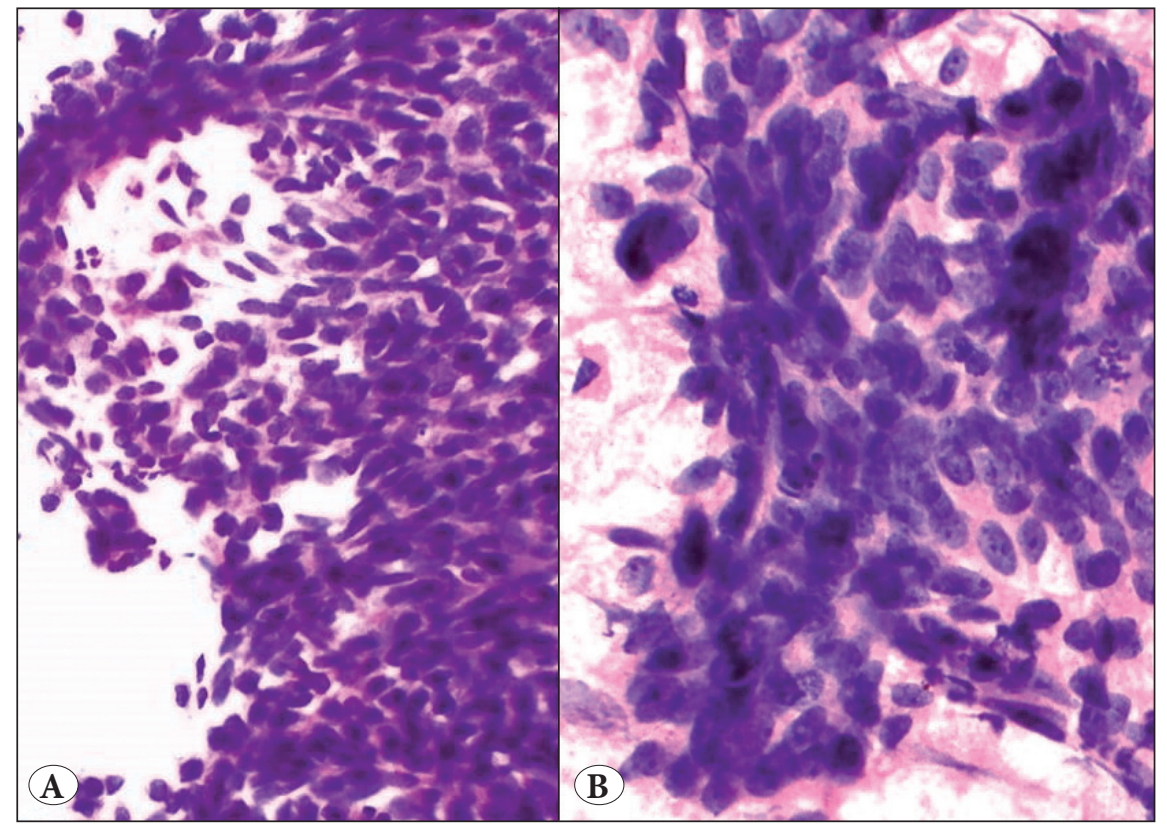

Figure 5: USG guided FNAC of ovarian masses. A) Endometriosis showing sheets of epithelial cells with few spindle cells (H\&E; x100).

B) Ovarian carcinoma showing clusters of atypical epithelial cells (H\&E; $\mathrm{x} 400)$. through image guided FNAC and found a sensitivity and specificity of $80 \%$ and $59 \%$ respectively when a combination of clinical and radiological features were taken into account (1). Ahmad et al. studied 200 patients with abdominal masses who were subjected to USG guided FNAC. The cyto-histological correlation revealed an overall sensitivity of $94.11 \%$, specificity of $100 \%$ and diagnostic accuracy of $95.7 \%$ (2). Parajuli et al also studied the role of USG as well as CT guided FNAC in intra-abdominal and intrathoracic lesions over a period of 4.5 years, including 53 abdominal and 47 thoracic masses (5). Hemalatha et al. evaluated USG guided FNAC of abdominal and pelvic masses and reported the diagnostic accuracy as $100 \%, 96 \%$, and $94.4 \%$, respectively for benign, malignant, and non neoplastic lesions (6).

On search of the literature, we came across few studies on USG guided FNAC of thyroid. Guided FNAC for thyroid lesions is usually recommended for lesions which are difficult to palpate or following a non-contributory palpation guided FNAC. However, any thyroid lesion with suspicious features on sonography like local invasion, microcalcifications, solid component, marked hypoechogenicity, increased vascularity, lymph node metastasis, etc. should be considered for USG guided FNAC $(13,14)$. Kim et al. in their review of USG guided FNAC of thyroid nodules concluded that this technique is useful for the diagnosis of palpable as well as non palpable nodules (9). The routine use of this technique can significantly alter patient management. Lee et al. compared the cytological results of USG guided FNAC of thyroid nodules to sonographic findings (10). They found that the positive and negative predictive values of the USG categories were $59.1 \%$ and $97 \%$ and those of cytological results were $93.7 \%$ and $98.9 \%$. The USG categories were significantly correlated with the final diagnosis in the benign $(p=0.014)$ and suspicious for malignancy $(p<0.001)$ cytological results group. In the present study, USG guided thyroid FNAC was performed in 10 cases and yielded a variety of diagnoses ranging from non neoplastic to neoplastic lesions. Only one case was inconclusive. The distribution of the thyroid cases is a bit unusual, and this could be due to the fact that we considered only guided FNACs for which non-guided FNAC was either noncontributory or could not be performed (due to small size or deep seated location). An interesting observation was that USG guided FNAC of the thyroid was very helpful in two cases of papillary carcinoma which did not yield diagnostic material on palpation guided FNAC but were subjected to image guided FNAC on account of the doubtful looking thick colloid and radiological suspicion. Cytohistological concordance was reached in the five cases where histopathology was available. These cases included 3 cases of papillary carcinoma, and 1 case each of Hurthle cell neoplasm and follicular neoplasm.

CT allows the performance of FNAC in situations in which USG or conventional $\mathrm{x}$-rays do not correctly visualise the lesion or the needle tract. Most of the studies in the literature on CT guided FNAC have applied it to evaluate lung lesions (15-19). In our study as well, CT guided FNAC was performed only for lung lesions. 
Table IV: Image guided FNAC: Cytohistopathological correlation

\begin{tabular}{|c|c|c|c|c|c|}
\hline & Site of FNAC & $\begin{array}{c}\text { Cytology } \\
(\mathrm{n}=54)\end{array}$ & $\begin{array}{l}\text { Histopathology } \\
\quad(n=32)\end{array}$ & Consistent & $\begin{array}{c}\text { Inconsistent } \\
\text { (Possible explanation) }\end{array}$ \\
\hline 1. & Liver & 14 & 6 & $\begin{array}{c}5 \\
(4 \text { metastastic adenocarcinoma, } \\
1 \text { hepatocellular carcinoma) }\end{array}$ & $\begin{array}{c}1 \text { (benign hepatocytes on } \\
\text { cytology; adenocarcinoma } \\
\text { on histopathology; maybe } \\
\text { needle could not reach } \\
\text { lesion) }\end{array}$ \\
\hline 2. & Thyroid & 10 & 7 & $\begin{array}{c}7 \text { (3 papillary carcinoma, } 2 \\
\text { hurthle cell neoplasm, } \\
1 \text { follicular neoplasm, } \\
1 \text { colloid nodule) }\end{array}$ & 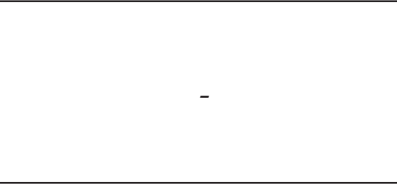 \\
\hline 3. & Lung & 8 & 4 & $\begin{array}{c}3 \text { ( } 2 \text { Adenocarcinoma } \\
1 \text { squamous cell carcinoma) }\end{array}$ & $\begin{array}{l}1 \text { (inflammation on } \\
\text { cytology, squamous } \\
\text { cell carcinoma on } \\
\text { histopathology; cystic } \\
\text { change and exudates } \\
\text { masked malignancy) }\end{array}$ \\
\hline 4. & Gall bladder & 6 & 5 & $\begin{array}{c}5 \text { (3 Adenocarcinoma } \\
2 \text { poorly differentiated } \\
\text { carcinoma) }\end{array}$ & - \\
\hline 5. & Lymph node & 4 & 3 & $\begin{array}{c}3 \text { (1 metastatic papillary } \\
\text { carcinoma thyroid, } \\
1 \text { metastatic adenocarcinoma, } \\
1 \text { tuberculosis })\end{array}$ & - \\
\hline 6. & Gastrointestinal tract & 3 & 2 & 2 (Adenocarcinoma) & - \\
\hline 7. & Ovarian & 2 & 2 & $\begin{array}{l}2 \text { (1 endometriosis, } \\
1 \text { carcinoma })\end{array}$ & - \\
\hline 8. & Retroperitoneal & 2 & 1 & 1 (Sarcoma) & - \\
\hline 9. & Epididymis & 2 & 1 & 1 (tuberculosis) & - \\
\hline 10. & Prostate & 1 & 1 & 1 (benign hyperplasia prostate) & \\
\hline 11. & Miscellaneous & 2 & 0 & - & - \\
\hline
\end{tabular}

FNAC: Fine needle aspiration cytology.

Arslan et al. evaluated a total of 316 cases of CT guided FNAC of lung lesions and found that the sensitivity for malignancy and specificity for benign lesions were $88 \%$ and $100 \%$, respectively (17). Positive and negative predictive values were $100 \%$ and $53 \%$, respectively. They concluded that the procedure has high diagnostic accuracy and an acceptable rate of complications. Wallace et al. studied the accuracy of percutaneous CT-guided fine-needle aspiration biopsy (FNAB) of small $(<$ or $=1.0-\mathrm{cm}$ in diameter) pulmonary lesions and concluded that it can yield high diagnostic accuracy rates approaching those of larger lesions (18). We encountered 8 cases of CT guided lung, out of which one case was inconclusive due to inadequate sampling. There was one false negative case (inflammatory on cytology and malignant on histopathology). This could be due to cystic change and dense exudate in a squamous cell carcinoma that masked the malignancy.

Mangla et al. conducted an audit of USG guided FNAC over a period of one year in a general cytopathology service based in Delhi catering to a similar patient population as in the present study (20). They observed that only 112 USG guided FNACs were performed out of a total of 7795 FNAC. The most frequent sites were intraabdominal (40.17\%), followed by thyroid (32.14\%), breast (9.82\%), superficial lymph nodes (8.92\%) and soft tissue and miscellaneous lesions (8.92\%). The cytology reports were diagnostic in $39.28 \%$, non diagnostic descriptive in $31.25 \%$ 
and inadequate in $29.46 \%$. They emphasized that there should be an attempt to improve documentation of all relevant clinical, radiological details and indication for guided FNAC on the cytology forms.

In conclusion, although the present study included a variety of organs where guided FNAC was performed, larger series are required for each organ to arrive at definite conclusions. The small sample size for each organ served as the limitation for this study.This article may help in creating awareness of this modality and thereby improve its applications for all such deep seated lesions where it was not possible earlier, so as to benefit the patients using cost effective and simple techniques. Moreover, the need to have complete documentation of clinical and radiological details on the cytology requisition forms cannot be overemphasized.

\section{REFERENCES}

1. Sheikh M, Sawhney S, Dey P, al-Saeed O, Behbehani A. Deepseated thoracic and abdominal masses: Usefulness of ultrasound and computed tomography guidance in fine needle aspiration cytology diagnosis. Australas Radiol. 2000;44:155-60.

2. Ahmed SS, Akhtar K, Akhtar SS. Ultrasound guided fine needle aspiration biopsy of abdominal masses. JK Science. 2006;8:200-4

3. Adhikari RC, Tuladhar A, Shrestha S, Sharma SK. Deep-seated thoracic and abdominal lesions: Usefulness of ultrasound guided fine needle aspiration cytology, a 3 year experience. Nepal Med Coll J. 2010;12:20-5.

4. Sobha Rani G, Md K Faheem N, Sai Prasad B V, Sudhakar Reddy E. Efficiency of ultrasound guided aspiration cytology in deep seated lesions-a diagnostic evaluation. Int J Med Health Sci. 2012;1:1-12

5. Parajuli S, Tuladhar A, Basnet RB. Ultrasound and computed tomography guided fine needle aspiration cytology in diagnosing intra-abdominal and intra-thoracic lesions. J Pathol Nepal. 2011;1:17-21.

6. A L H, Sindhuram V S, S S, J K S, I V, Aditya A. Ultrasound guided fnac of abdominal-pelvic masses-the pathologists' perspective. J Clin Diagn Res. 2013;7:273-7.

7. Mehdi G, Maheshwari V, Afzal S, Ansari HA, Ahmad I. Imageguided fine-needle aspiration of retroperitoneal masses: The role of the cytopathologist. J Cytol. 2013;30:36-41.

8. Jha BM, Shah R, Patel J. Effectiveness of image guided fine needle aspiration cytology in cases of deep seated lesions. Int J Med Sci Public Health. 2013;2:439-42.
9. Kim MJ, Kim EK, Park SI, Kim BM, Kwak JY, Kim SJ, Youk JH, Park SH. US-guided fine-needle aspiration of thyroid nodules: Indications, techniques, results. Radiographics. 2008;28:1869-86.

10. Lee MJ, Hong SW, Chung WY, Kwak JY, Kim MJ, Kim EK. Cytological results of ultrasound-guided fine-needle aspiration cytology for thyroid nodules: Emphasis on correlation with sonographic findings. Yonsei Med J. 2011; 52:838-44.

11. Degirmenci B, Haktanir A, Albayrak R, Acar M, Sahin DA, Sahin O, Yucel A, Caliskan G. Sonographically guided fine-needle biopsy of thyroid nodules: The effects of nodule characteristics, sampling technique, and needle size on the adequacy of cytological material. Clin Radiol. 2007;62:798-803.

12. Ghosh A, Ghartimagar D, Shrestha MK, Tiwari PK, Narasimhan $\mathrm{R}$, Talwar OP. Value of image-guided fine-needle aspiration cytology-a study of 500 cases. Diagn Cytopathol. 2013;41:105262.

13. Baloch ZW, Cibas ES, Clark DP, Layfield LJ, Ljung BM, Pitman $\mathrm{MB}$, Abati A. The National Cancer Institute Thyroid fine needle aspiration state of the science conference: A summation. Cytojournal. 2008;5:6.

14. Chaudhary V, Bano S. Thyroid ultrasound. Indian J Endocrinol Metab. 2013;17:219-27.

15. Tsukada H, Satou T, Iwashima A, Souma T. Diagnostic accuracy of CT-guided automated needle biopsy of lung nodules. AJR Am J Roentgenol. 2000;175:239-43.

16. Mostafa MG. Computed tomography guided fine needle aspiration cytology in the diagnosis of thoracic lesions. J Indian Med Assoc. 2001;99:550-1, 553.

17. Arslan S, Yilmaz A, Bayramgürler B, Uzman O, Nver E, Akkaya E. CT- guided transthoracic fine needle aspiration of pulmonary lesions: Accuracy and complications in 294 patients. Med Sci Monit. 2002;8:CR493-7.

18. Wallace MJ, Krishnamurthy S, Broemeling LD, Gupta S, Ahrar K, Morello FA Jr, Hicks ME. CT-guided percutaneous fineneedle aspiration biopsy of small $(<\mathrm{or}=1-\mathrm{cm})$ pulmonary lesions. Radiology. 2002;225:823-8.

19. Bandyopadhyay A, Laha R, Das TK, Sen S, Mangal S, Mitra PK. CT guided fine needle aspiration cytology of thoracic mass lesions: A prospective study of immediate cytological evaluation. Indian J Pathol Microbiol. 2007;50:51-5.

20. Mangla G, Arora VK, Singh N. Clinical audit of ultrasound guided fine needle aspiration in a general cytopathology service. J Cytol. 2015;32:6-11. 